\title{
Making scenario interventions matter: exploring issues of power and rationality
}

Running head: Making scenario interventions matter

\author{
George Cairns ${ }^{1}$ \\ George Wright ${ }^{2}$ \\ 1. QUT Business School, Queensland University of Technology, Brisbane, Australia \\ Email: george.cairns@qut.edu.au \\ (corresponding author)
}

2. George Wright, Strathclyde Business School, University of Strathclyde, Glasgow, UK 


\title{
Making scenario interventions matter: exploring issues of power and rationality
}

\begin{abstract}
:
In this article, we consider prospects for long-term impact from scenario projects, specifically for sustained positive change. We outline scenario methods intended to actively engage scenario development team members who will be directly impacted by the 'focal issue' of the scenario exercise, in particular those who are remote and by and large excluded from the central decision making processes of the powerful. We consider possibilities for building capacity for them to envisage and enact alternative futures for themselves and their communities. However, we see a need to consider how current powerful actors might respond to the wishes and actions of less powerful stakeholders, positing that the potential for action by these less powerful groups may be disrupted by the rationality of the more powerful, where any intended action is against the latter's interests. We argue that understanding and appreciating issues of power and rationality are central to how such participatory approaches might elicit coordinated and articulated action in response to positive scenarios. We discuss this issue by reference to contemporary interpretations of Aristotelian phronessis, or 'practical wisdom'. We outline steps involved in enacting an augmented scenario model that responds to this critique.
\end{abstract}

Keywords: scenario, power, rationality, agency, stakeholder, phronēsis

\section{Introduction}

In this article, we consider developments in scenario methods that are intended to actively engage those stakeholders who are directly involved with and, specifically, affected by the 'focal issue of concern' (Cairns \& Wright, 2018) of the scenario exercise, but who are by and large remote and excluded from the decision-making arena. Scenario methods have proved popular in the field of strategic planning over decades - variously, engaging senior decision makers in large organizations (e.g. Gershman, Bredikhin \& Vishnevskiy, 2016; Schoemaker \& van der Heijden, 1992), governments (e.g. Rickards, Wiseman, Edwards \& Biggs, 2014; Venable, Ma, Ginter \& Duncan, 1993), and multi-organizational collaborations (e.g. Cairns, Wright, Fairbrother \& Phillips, 2017; Kahane, 1998a, 2012).

From examples of high-profile scenario projects, the positive benefits for the Royal Dutch Shell group are much cited (e.g. Cornelius, Van de Putte, \& Romani, 2005; Schoemaker \& van der Heijden, 1992) and the model has retained its currency (e.g. Jefferson, 2012), while the Mont Fleur scenarios for a post-apartheid South Africa are widely reported (e.g. Kahane, 1998b; Van Der Heijden, 2000). In relation to the former, the company continues to ride high in the field of oil and gas (cf. Poole, 2018) and to use scenarios in its strategic planning (Shell Global, undated). However, in relation to the latter example, we would question the long-term benefits for the population at large in South Africa, as evidenced by the nation's declining position in Transparency International's corruption perceptions index (Conway-Smith, 2014) and its slide to $105^{\text {th }}$ of 156 nations in the UN's World Happiness Report - behind Somalia, Pakistan and China (de Villers, 2018). 
In terms of taking account of more remote stakeholder groups, there has been growing interest in the use of scenario methods as forms of 'participative engagement' (Bourgeois, Penunia, Bisht and Boruk, 2017; Oteros-Rozas, Martín-López, Daw, Bohensky, Butler, Hill, Martin-Ortega, Quinlan, Ravera, Ruiz-Mallén \& Thyresson, 2015). We read participative engagement to be a process of active development of scenarios with the community that 'owns' the focal issue. To work truly with a community involves acknowledging their expertise, experience, beliefs, values and priorities and their notions of what is good and desirable. However, as we will discuss, this is not necessarily to prioritise these over others, nor is it to condone moral relativism where all ideas are considered equal. Rather, it is to ensure first and foremost that external expertise is considered in tandem with local, contextual knowledge of the affected community, not simply applied for them and certainly not 'done to them'.

Bourgeois et al. (2017) present case study examples of participative engagement, based on their work with "local actors at grassroots level" (p.178) in farming communities in India, Indonesia and the Philippines. They outline three programs that demonstrate a process of local engagement with the involved actors, using an action research (Ramos, 2006; Stevenson, 2006) approach. However, while local actions were noted as having been implemented in response to the exercises, the article states that, "it is too early for a thorough assessment of evidence of these local organizations as key players in a societal change shaped by the understanding of future challenges" (p. 185). In critically appraising examples of participative engagement, Oteros-Rozas et al. (2015, Appendix 9) revisited and analysed 23 projects conducted between 2003 and 2014. They found evidence of long-term impacts beyond one year after completion in only two of these. Whatever the evidence of impact, these examples provide reports of real-world engagement and conversion of method to action.

The approach termed 'critical scenario method' (CSM) (Cairns, Śliwa \& Wright, 2010; Wright \& Cairns, 2011) is designed to require consideration of the impacts of each of a set of scenarios on the 'broad' (Freeman \& Reed, 1983) stakeholder constituency. However, CSM remains conceptual in nature, with no empirical evidence of its efficacy in practice. As such, while remote stakeholders' potential interests and impacts of action on them are addressed, they are usually treated as subjects of research, not necessarily as active participants in the process.

Developing consideration of the effectiveness of scenario methods as means of engaging multiple stakeholder groups, with diverse values and interests, we posit that it is essential to take account of issues of power, politics and the rationality of different arguments. We live in an era that is pervaded by reference to 'alternative facts' (e.g. Swaine, 2017) and 'post-truth' politics (e.g. Montgomery, 2017; Suiter, 2016), where a prominent lawyer and U.S. Presidential advisor can claim that, "truth isn't truth" (BBC News, 2018). As we will argue, failure to consider the potential of such alternative rationalities and truths and the likely actions, linked to particular viewpoints, by powerful stakeholders risks the failure of any scenario project.

Based on extant examples, we cannot state that scenario interventions have not produced long-term, sustainable benefits for broad society and the environment, but find limited confirmation that they have. Such success, or lack thereof, would require retrospective review 
of a broad sample of projects a decade or more beyond their completion. However, since scenarios are widely used as a strategic analytic tool in the practice arena, we seek to maximise the potential for future projects to promote sustained and positive change. In developing our model for such potential, we draw on Aristotle's philosophy and his 'intellectual virtue' of phronessis - thinking to inform action for the greater good - and on contemporary social science interpretation by Flyvbjerg (1998, 2001, 2003). While Aristotle establishes the philosophical foundations for consideration of what is 'good' and for whom, Flyvbjerg introduces issues of power and human rationality to critical discussion of how phronetic thinking might be enacted, or foiled.

From our deliberations, we develop six premises to underpin a conceptual model that we outline to support deep and ongoing engagement towards long-term impact for broad 'good'. We term our conceptual model 'Power-Rationality Scenario Analysis' (PRSA)

\section{Philosophical foundations for an enhanced scenario approach}

Our intent here is to support the mode of action research-based scenario engagement, while expanding the process to embed critical inquiry into issues of power and interest, agency and rationality. Specifically, we seek to promote critical assessment of the range of potential responses to proposed local actions by involved stakeholders from those external to the context, but who have power over how these actions might be resolved. These parties may act positively (from the perspective of the 'local actors') or, more critically, negatively, to protect their own interests through reaffirmation of the status quo. Additionally, they may be overtly supportive of the local agenda in public, while working against it covertly within their own domain of power and influence.

From our discussion, we hope to enable committed scenario practitioners who aim for long-term beneficial impacts from their projects to be better prepared to engage with both the local and affected stakeholders and those at a higher level of authority and decision-making. Here, we must stress that resolution of any issue in terms of what is 'good' is not based on moral relativism, whereby all values are considered equal, but on deep thinking on the merits, or otherwise, of competing values and rationalities to establish a position of 'greater good' for the directly affected community of stakeholders. As such, in terms of the argumentation above, the proposed resolution of the focal issue may not be in terms considered 'good' by other sets of actors.

In developing our own line of discussion, drawing on the philosophy of Aristotle, we first outline his three 'intellectual virtues' that are specifically concerned with the nature of human knowledge. While the terms are common to other Greek philosophers, with some nuances in their definitions, we work with Aristotle's versions throughout. First, there is epistemee, or scientific knowledge that is universal and demonstrable. Such knowledge is context-free and unchanging across time and space. A basic example would be $2+2=4$. Second, we have techne, or knowledge of production of a final object. Here, an example would be the knowledge of the cabinet maker or the cordon bleu chef, both of whom apply specialist knowledge in order to produce something tangible. Both epistēme and technē have derivatives in contemporary language, in epistemology and technology and related terms. 
In contrast to both epistemē and technē, the third of Artistotle's knowledge virtues, phronesis, has no such legacy in modern languages. It is generally referred to in contemporary translation as 'prudence' (Aristotle, 1976/2004) or 'practical wisdom' (e.g. Dowie, 2000; Smith, 1999), neither of which to our minds captures the fundamental essence of the original. Aristotle (p. 150) refers to phronēsis as, "a true state, reasoned and capable of action in the sphere of human goods". "It is concerned with acts that are just and admirable and good for man (sic)" (p. 162). Hence, phronēsis is differentiated from epistēme, in that it is not general and abstract, but is contextual and directed at action for the good of humanity. Also, it differs from technē in that it has no tangible output in terms of product.

Here, we must further clarify that adopting an Aristotelian notion of good sits in contrast to the Platonic idea of a knowable, singular universal 'good' that can be unearthed through philosophical contemplation. Rather, for Aristotle, what is good is a contextual matter, subject to diverse interpretations that must be addressed through debate and dialectical inquiry. Our own thinking on the nature of phronetic inquiry and debate on the goodness, or otherwise, of different potential futures draws on Flyvbjerg's (2001) principles for 'making social science matter'. Flyvbjerg's consideration of this issue draws inspiration from his earlier study (Flyvbjerg, 1998) in which he undertook a retrospective analysis of a town planning program in Denmark. In this, he identified the paradoxical nature of arguments for and against particular proposals, presented as rational and coherent while the narratives of action were characterised by power, and post hoc rationalization presented as rationality. We consider that both Flyvbjerg's explication of Aristotle in the $21^{\text {st }}$ century and his approach to analysis of long-term project impacts are of value in considering a further augmentation of scenario method that seeks to foster advancement of 'good' outcomes while requiring longterm reflection on whether or not this is being achieved.

Flyvbjerg's (1998) longitudinal study of the planning process involved a narratological analysis of records and recollections from over almost two decades of the project. In using narratives - a form not unfamiliar to the scenario thinker - he acknowledges that narratives "not only give form to our past experience, they also help us envisage alternative futures" (p. 8). He again refers to futures narratives in his later work on phronetic social science, stating that they can help us to "anticipate situations even before we encounter them, allowing us to envisage alternative futures" (Flyvberg, 2001, p. 137). However, futures are not an area that he develops beyond these statements, while his work was fundamental to the development and theorizing of the CSM approach (Cairns et al., 2011).

Consideration of the nature and intent of phronessis and its potential in the field of scenario analysis leads us to outline our first premise underpinning the practical application of the PRSA approach to scenario development and use, namely:

Premise 1: PRSA is grounded in phronetic social inquiry

The specific aim of the PRSA model is to provide a framework for structured research, analysis and critical thinking on the 'focal issue', to inform action that is directed at achieving a 'greater good' for the directly affected stakeholder community.

While this premise sets out a broad philosophical foundation, it raises further questions regarding the nature of 'good', specifically whose definition of good should prevail, and 
whether one good should be permitted to diminish or nullify another. We discuss this and other issues below.

\section{Considering issues of power and rationality in scenario analysis}

Issues of power have been discussed in relation to scenario methods, specifically in the augmented intuitive logics method titled 'critical scenario method' (CSM) (Cairns et al., 2010; Wright \& Cairns, 2011), with reference to Flyvbjerg's (2001, 2003) contemporary interpretation of Aristotelian phronèsis.

Since phronēsis is concerned with moral-ethical thinking to inform action for the 'good of man' (sic), a key step in the CSM process is that each of the scenarios narratives is interrogated by application of Flyvbjerg's (2001, p. 60) set of value-rational questions directed at phronetic inquiry, namely:

1) Where are we going?

2) Is this desirable?

3) What should be done?

and,

4) Who gains and who loses; by which mechanisms of power?

In CSM, the consequences of actions by decision making stakeholders for those who are largely powerless and excluded are considered for each of four scenarios produced in line with the 'basic method' (Wright \& Cairns, 2011) of scenario development. The initial CSM approach has been further augmented by the incorporation of a numeric analysis (Cairns, Goodwin \& Wright, 2016; Cairns \& Wright, 2018), enabling quantification of the value attributes for achievement of different strategic options and outcomes for each stakeholder group.

While CSM is concerned with impacts on all stakeholders, it does not explicitly require participative engagement with those who own the focal issue of concern. As such, an exercise in applying CSM may end with a set of hypothetical actions proposed to specifically address normally-excluded stakeholders' interests, with some critical reflection on how these may be enacted or impeded by other, more powerful actors. However, there is no certainty that action will be taken, that these excluded stakeholders will become aware of others' thinking about them, let alone that proposed actions will have the desired outcomes.

The PRSA approach to scenario development and use that we present here embeds a step-by-step stakeholder identification and activation framework that builds on the aims of CSM (Cairns et al., 2010). It also draws on the work of Bourgeois et al (2017), specifically the enactment of scenario projects that did engage local stakeholders in remote regions. The case examples presented by Bourgeois et al. (2017) involve direct participative engagement with local communities, to address their own focal issue of concern. However, while there is clear presentation of the process of engagement and development of proposed strategic options for community betterment, these projects have not yet been subjected to long-term evaluation. What is considered 'good' is expressed in terms of the desires and values of the local communities and organizations that are included in the participative scenario process. 
We would posit that long-term success, or otherwise, in building sustainable benefit for the involved communities will in part be determined by the thinking and acting of more powerful actors at higher levels of authority - regional, state, federal, national, global. We would also argue that these parties' responses may be either rational or based on a human rationality that defines reality in terms of its own self-interest. They may be explicitly supportive, but subversively destructive. Also, they may bring outcomes as a result of either action or failure to act. It is to such issues that we turn our attention.

In developing our discussion here, and the model of inquiry derived of it, we will return to these questions and the principles underlying them to guide our thinking.

\subsection{Considering the nature of power relations within our context of thinking/acting}

In considering issues of power in relation to the potential for successful co-elaborative scenario building and subsequent strategy making, we must first clarify how we define and interpret the term 'power'. While some writers (e.g. Marx \& Engels, 1888/1967; Weber, 2009) focus on power in relations of domination and authority, others (e.g. Foucault, Morris \& Patton, 1979; Nietzsche, 1968) view power as a ubiquitous element of human interaction. Dahl (1967) argues against the elitist view of power and hierarchy, while Arendt (1970) proposes that power, "springs up whenever people get together and act in concert". Here, power is seen as offering potential for collaboration rather than being a purely conflictual element of human interaction. For us, building and evaluating scenarios requires that we consider both potential power relations of conflict and self-interest and of collaboration and mutual benefit. However, we suggest that conflictual power relations are unlikely to produce outcomes considered as mutual good by all parties. In line with Flyvbjerg (1998) and Vangen (Vangen \& Huxham, 2003, 2012; Vangen, Hayes \& Cornforth, 2015), we posit that positive outcomes for the future require first that stability of power relations be established between all involved and affected parties. Hence:

\footnotetext{
Premise 2: Realization of a future improvement in the overall human condition can only be based on creation of stable power relations, rather than confrontations

Successful enactment of a future that brings the maximum benefit to the greatest number can only be brought about under conditions of mutual respect and engagement between stakeholder groupings and lack of confrontation.
}

This may seem like a pipedream, particularly when looked at from the current perspective of international tension, religious and nationalistic extremism and conflicting beliefs in relation to matters ranging from climate change to what constitutes economic 'good'. However, we would argue that the perpetuation of such conditions is not inevitable c.f., the development of the European Union after World War II and, more recently, the context within South Africa when Kahane (2012) made the scenario intervention that we described earlier.

\subsection{Power, rationality and rationalisation}

In his earliest work considered here, Flyvbjerg (1998) presents an in-depth study of a project of urban renewal involving collaboration between a wide range of actors including, 
but not limited to; "the business community, grass-roots organizations, political parties...[] trade unions, the police, various local and national consultants, interested citizens, the media" (p. 9) and a range of formal organizations at the local, national and international levels. This study covers a period of more than a decade, from project inception through various stages of design and redesign, partial implementation, and degrees of success and of failure. His sources include archival documentation from official, unofficial and media outlets and a set of in-depth interviews with key actors. Flyvbjerg concludes that, "the very language we use to understand reality - the written and spoken word - is itself characterised by rationality and coherence, whereas reality is often characterised by power and fragmentation" (p. 8). From this, we draw our third premise:

\footnotetext{
Premise3: Stable power relations at the project level may be subject to alternative expressions of rationality at a higher level

While a scenario project may be explicitly grounded in agreed collaborative democracy, there may be political, economic or social agendas for participant organizations at a higher level that are not commensurable with the bounded rationality of the scenario project.
}

While we argue for stable power relations (i.e., where there is no overt conflict between stakeholders who, perhaps, have different levels of power) and respect within those taking part as members of the scenario development project, we recognise that these may be underpinned by conflicting power relations at the national and international levels. At these higher levels, values, beliefs and legislative frameworks may favour: extant powerful groups and individuals at the national level; international institutions like the World Bank and International Monetary Fund (IMF), or; multinational corporations with an interest in either the markets or the resources - or both - on which their local representatives are reliant. These higher-level interests may be in direct conflict with the agenda of the local, affected community - including the local representatives of national and international organisations who may be part of a particular scenario project. Such higher-level interest, and so plausible active involvement, may act to de-rail local collaborative initiatives. For this reason, any scenario project should, in our view, seek to involve the most senior representatives of stakeholder groupings.

\subsection{Power and reality}

Flyvbjerg (1998) asserts that, rather than being a basis for uncovering and describing reality, power is itself the basis by which reality is defined. He states (p. 227) that, "power defines what counts as rationality and knowledge and thereby what counts as reality" (emphasis in original). Here, we might consider events that have unfolded in the two decades since this was written, such as the matter of 'weapons of mass destruction' in Iraq, and the current debates around what constitutes 'alternative facts' (Swaine, 2017) and 'fake news' (Allcott \& Gentzkow, 2017). In relation to scenario analysis intended to inform action for the good of society and humanity at large, the potential disruption by strong vested interests and their power networks cannot be underestimated or ignored. Such interests may not necessarily be outlined in terms of opposition to any other stance and they may not preclude 
consideration of alternatives, but they inform the discourse and power relations of those committed to them.

As Flyvbjerg (1998) argues that reality is not based on a single rationality but, rather, that what is deemed reality is determined by power relations and a dominant rationalization presented as reality, so Beech and Cairns (2001) present four 'levels' of reality, based on discussion of case examples from their experience. These four levels consist of:

1. Single reality - where every individual perceives the same 'reality'. These authors deem such a possibility rare - and transient

2. Multi-layered reality - where different actors see largely the same reality, but with minor differences of perception and value attached to its characteristics

3. Multiple realities - where a common set of terminologies and symbols are subject to very different interpretations and value attributions - realities may seem similar on the surface, but are underpinned by very different rationalities

4. No-such-thing-as-reality - where even individuals play 'language games' and present different rationalities and 'reality narratives' in response to a single stimulus to different audiences.

While the scenario development team and the involved stakeholders may hope and act towards ensuring that the emergent reality is in line with what is seen as a desired scenario, it is likely that the reality that does unfold through the dominant power/rationality will inform retrospective judgement on whether such a scenario was in fact desirable - for example, interpretations of the outcome of recent Western interventions in Iraq (cf. Roth, 2004) and Libya (cf. Bellamy, 2011).

We would argue that the key challenge in building a successful and ongoing collaborative PRSA scenario program is to accept that there is no 'single reality', that there is a definite need to avoid falling into the politics and power games of 'no-such-thing-as-reality' and to accept and live with the realization that 'reality' is a multiple concept that lies somewhere it the realms level 2 or 3, depending on what the stakeholder constituency under consideration is, and how their power/rationality relations are constructed. We therefore advocate that scenario development is not a process bounded by time and informed by a specific rationality but an ongoing interaction between narratives of possibility and emergent reality. However, in line with Premise 1, above, the central aim must be to steer the future toward one that offers the greatest improvement in the human condition for the greatest number. Hence, we posit:

Premise 4: A better future is not based on a single reality, but on acceptance of multiple realities Achievement of a better future outcome for the greater good requires recognition and acceptance of the multiplicity of values and beliefs that underpin individual and group thinking, and that inform different world views.

We offer no prescription, no panacea for resolution of the issues outlined to here, of how to develop stable power relations and to address the multiple rationalities and realities of different stakeholder groups. However, we posit that these must be addressed before relative 
inequalities can be an accepted topic of inter-stakeholder debate - between advantaged and disadvantaged stakeholder groupings. In short, the facilitation of face-to-face inclusive dialogue between stakeholder groupings where the power relations are stable and senior participants (see Premise 3, earlier) have respect for each other (see Premise 2, earlier) is, in our view, the best foundation on which existing and future inequalities can be successfully debated. Only in such exchanges will each side be able to fully appreciate and understand each others' viewpoints, i.e., each others' alternative rationalities (see Premise 4, earlier).

Having considered the nature of power relations between stakeholder groups and their role in determining what is considered rational and logical, and who will benefit in terms of their own 'good', we now turn to further elaboration of stakeholder identification and analysis.

\section{Expanding and embedding stakeholder analysis and engagement}

We would assert that stakeholder analysis should form an integral part of the scenario process, intended to ensure that thinking within a project is not confined to - or constrained by - consideration of the interests of only those with direct involvement. Adopting the 'broad' stakeholder approach (Freeman \& Reed, 1983) takes our thinking beyond only those who can directly impact the situation and those who will be immediately affected. It challenges us to consider third parties and beyond: those who may lie at the end of a long chain of cause and effect, and of whom we may not even be aware at the outset; and those who may be impacted in the future by decisions that are taken in the present.

\subsection{Stakeholder identification}

In considering the broad view of stakeholders in relation to the issue at hand, we must take account not only of those with direct financial, employment or benefit interests - those who can affect the focal issue through their actions - but also those who have no effect on the situation, but who may be impacted or affected by its outcomes, both now and in the future. Stakeholder groupings can be defined in generic terms, such as 'management', 'customers' and 'media'. However, in order to engage meaningfully with stakeholder issues, it is necessary to think about sub-divisions within such groupings. In doing this, we will uncover those sub-groups who will have particular interests and different levels of power.

The power/interest matrix (Figure 1) promotes consideration of the level of interest different stakeholders have in what happens within a focal scenario, and their degree of power to influence the situation. Discussion should be constructed around joint consideration of who the various stakeholders are, and where they lie within the matrix at a given point in time. It is probably best to start with the present time as the context for this, so that issues of power and interest can be discussed in relation to what is currently known.

\section{INSERT FIGURE 1 ABOUT HERE}

\subsection{Stakeholder activation}

It is crucial to consider that stakeholder relations are not fixed but are dynamic and can be influenced by numerous factors, from the rational to those grounded in a rationality of 
expediency. Here, we might usefully consider whether a particular, radical course of action proposed by decision-makers ('players') will be supported by currently dormant 'context setters' or might provoke negative responses and challenge from them. Where discontented context setters move to become players to protect their own interests, might such a move provide opportunity for power-seeking 'subjects'? Is it possible and plausible to contemplate an alliance between these two groups to resist the proposed change? Remember that such an alliance might be either one of shared values and wishes with long-term potential, or one of political expediency for short-term gain.

Application of the power/interest matrix allows us to consider not only who the obvious decision-makers are, but also who might be alternative power-brokers if their dormant interest in business-as-usual is aroused and converted to active interest under some other scenario conditions. Finally, it enables us to identify those stakeholders with high levels of interest in a situation, but who lack power. In relation to this group, the introduction of CSM provides a vehicle for consideration of issues of 'winners' and 'losers' within different scenarios through interrogation of their trajectory, and of the desirability or otherwise of their outcomes for different groups. It enables us to compare and contrast alternative forms of action within various scenarios and requires us to address the issue of power - who holds it, how they use it, and what impact it has on others. Figure 2 sets out our conceptualization of stakeholder activation.

\section{INSERT FIGURE 2 ABOUT HERE}

There are a number of key issues that should be considered in implementing full stakeholder analysis. First, the relationship between stakeholder analysis and scenario narrative is symbiotic, in that understanding of stakeholder power relations and areas of interest can inform the building of scenario narratives (see Chapter 3 of Cairns and Wright, 2018 , for a step-by-step method for incorporating the scenario team's current views of anticipated stakeholder reactions to unfolding scenario outcomes into scenario storylines). At the same time, the publication or circulation of developed scenario narratives may serve to inform stakeholder thinking and, thereby, their future degrees of interest and thus the nature of emergent power and interest relations. Stakeholder analysis can alert us to possible political activity, whereby disempowered 'subjects' might try to unite with disaffected 'context setters' to challenge the status of current 'players'. Second, it has the potential to alert us to genuinely disadvantaged subjects whose interests are ignored at present.

\subsection{From stakeholder analysis to stakeholder engagement}

Moving beyond simply identifying stakeholders and considering their degrees of power and interest from afar, here we are concerned with how to bring them into the process of participative engagement. The first step is to consider each of the stakeholder types and to identify all identified stakeholders with interest and power in respect of the focal issue of importance to the scenario development team. The second step is to consider each stakeholder's current level of interest and power and identify suitable actions for the scenario 
project team - in terms of monitoring, collaborating, defending and persuading. Table 1 sets out this identification/action process in detail.

\section{INSERT TABLE 1 ABOUT HERE}

The activities set out in Table 1 are, in our view, most relevant in scenario projects where the many stakeholder groups are external and so not part of the team involved with the scenario development process. Bourgeois et al. (2017) present case studies where affected communities become the scenario developers themselves - the 'local actors at grassroots level' that we refer to above. In contrast, Kahane (1998b, 2012) presents studies where all involved and affected stakeholders are part of the scenario development team, rather than as in the Bourgeois case - where only the grouping of the less-powerful are the scenario developers. In Kahane's work in South Africa in the era of white rule, one scenario - named 'Icarus' - was very negative, and instrumental in all the stakeholder groupings realizing that, by their articulated actions, they could seek to avoid a future where a social spending spree led to balance of payments problems and currency depreciation after the transition to black majority rule. Kahane's (2012, p. 75) approach is to get the full range of stakeholder groups involved in the scenario development process such that, " $(\mathrm{t})$ he contribution of the scenario project is not that it has gotten actors to act, this is what they have been doing and continue to do. Instead its contribution is to help actors to act with broader, deeper and more aligned understandings, relationships and intentions, with greater wisdom". As we noted earlier, in Section 3 above, such face-to-face engagement between stakeholder groupings is ideal but, in our experience, unusual in practice.

\subsection{From scenario analysis to action - fostering stakeholder relevance and response}

Rickards et al. (2014) argue that multi-agency participants in a scenario development project need to perceive the common scenario intervention to be rigorous, salient and legitimate - the latter taken to be the fair and unbiased treatment of diverse views and interests. Bryant and Lempart (2010, p.35) note that the "diffuse and heterogeneous nature of public agencies' objectives and interests may make it impossible for them to come to a consensus about the meaning of scenario axes." Rickards et al. (2014, p. 653) also state that other reasons why "(s)cenario planning can struggle to inform adaptation decision making in an evidence-based policy environment" include; i) the lack of an organizational champion to foster continuing interest once the initial scenario development is complete, and ii) lack of immediate opportunity to implement strategic change within existing planning cycles. Kahane (2012) is clear that 'action' was difficult to engender in his discussion of scenario exercises that were meant to challenge and change the future of countries - South Africa and Columbia. His prescription is for the scenario development team to 'seed' country-wide discussions: in the South African 'Mont Fleur' scenario intervention that we introduced earlier, he notes that:

(W)e distributed 20,000 copies of our full 80-page report, 10,000 copies (in five languages) of a 32-page summary report, and 2,000 copies of a 30-minute video; we ran more than 100 workshops for political, business, non-governmental, and community 
organizations in every province and every major city; we created five weekly inserts in a national chain of newspapers (with 2 million readers) and six weekly televised debates. (p.70)

In the case of our own scenario intervention, with others, in North West Tasmania (Cairns et al., 2017), the process was trusted by the multi-agency stakeholder groupings, was politically backed, was not threatening to vested interests, was well-facilitated, and involved appropriate participants. However, there was no one single individual or organizational 'champion' - as there usually is within a single organizational-level intervention (cf. Wright and Cairns, 2011) - nor was the opportunity for a subsequent single (major) action clear. For this reason, the benefits of Kahane's 'seeding' approach to activating dormant context setters resonates with us in our critical reflection on our regional - rather than country-wide scenario intervention. Building on these examples, we would argue that stakeholder identification and activation is not a once-only engagement but an ongoing and unfolding essential element of the scenario process.

\subsection{Engaging stakeholders as a long-term commitment}

Most presentations of the outcomes of scenario projects involve development of scenario narratives within a particular time frame, ranging from a few hours to many months. Thereafter, the scenarios are presented in terms of evidence of - or assumptions about - how they have informed developing strategy, policy or planning. However, in our practical experience and from our literature searches, we find no evidence of this type of longitudinal engagement with, and evaluation of, what actually unfolds after the formal project is completed. In our analysis, the unfolding reality will be strongly influenced by the power relations and dominant rationalities, rather than the prospective hopes of a reality that is derived from the best-case scenario and initial actions from within the scenario development team.

Premise 5: Scenario outcomes that result from the actions of stakeholders (either external to or part of the scenario project team) can be part of long-term extended activities, rather than being one-off or shortterm

While many scenario project reports outline engagement over extended periods, with multiple iterations of scenario development, there is a need for extended monitoring and engagement with stakeholders after the scenario development exercise is concluded - as strategies, policies and actions are implemented.

\subsection{Ensuring an inclusive stakeholder input - where engagement is not possible}

The fundamental basis of Bourgeois et al.'s (2017) participatory engagement model is based on an action learning approach along with affected stakeholders. This is relatively easy where those stakeholders involved in the scenario development process are, solely, the local community and local organizations, so long as there is both a desire and a commitment to active engagement by all parties. However, here we require that stakeholder analysis is extended to include the 'broad' community of stakeholders - "any identifiable group or individual who can affect the achievement of an organization's objectives or who is affected by the achievement of an organization's objectives" (Freeman \& Reed, 1983, p. 91). For a complex project that aims to address some societal issue with the aim of improving the 
human condition, the list of such stakeholders will likely be extensive, and encompass a vast geographic area. As we have argued, ideally all stakeholders should be engaged in the scenario development team (c.f., Kahane's approach and work, discussed earlier) but practicality will likely exclude the possibility of such general engagement. Rather than then moving to a state of exclusion of some stakeholders, we advocate the use of role-play of those who are unable to participate by some of those in attendance. Green \& Armstrong (2011) demonstrate empirically that those that role-play others make accurate decisions about how these others might think and act than if they merely 'role-think' their possible responses.

In their underpinning research, Green and Armstrong's (2011) focus was on 'forecasting' the actual decisions made in real, but historic, conflict situations - with participants instructed to indicate, "which decision you think that each party in the situation would prefer to be made and how likely is it that each party's decision will actually occur" (p. 73). An example conflict situation was that of angry nurses increasing their pay demand and threatening further strike action after specialist nurses and junior doctors received a big pay increase. Participants in the role-thinking were asked to predict the outcome of negotiations between the stakeholder groupings after having read role descriptions of each grouping. The role descriptions detailed recent context and actions. However, the directive to participants to engage in 'role-thinking' resulted in forecasts that were no more accurate than guesses. In contrast, when students were required to become more engaged with the conflict situations by 'role-playing' or simulating the interactions between participants in the conflicts - the predictive accuracy of the role players' in-role decisions reached $90 \%$. In the role-playing simulation, each student was assigned a single role and the role-players interacted with each other in a similar way to actors on a stage.

Somehow, role-playing brought out the best from the university students - in that their simulations of conflict situations resulted in resolutions of the conflicts that were close to real-life resolutions. Green and Armstrong's (2011) students could not be expected to have strong technical or domain knowledge about each, or all, of the conflict situations. Intuitively, an understanding/enactment of stakeholder motivations/behaviour seems more fundamental to predicting/resolving the actual outcomes of conflicts than either technical or domain knowledge. Intuitively, it would seem that one's own experiences of the past resolution of conflicts - perhaps as recalled or previously experienced and including personal as well as non-personal conflicts - would be a strong guide to the prediction/resolution of the outcomes of conflicts, since Maslow's hierarchy of needs underpins all of human behaviour. Thus, it seems intuitively reasonable that only when individuals are enmeshed in role-play simulations will the relevance of this experience become obvious - since Green and Armstrong's conflicts will, initially, have been seen as outside the domain of this experience at a superficial, face-content, level.

While we strongly advocate for full and direct stakeholder involvement, we acknowledge that this may not always be possible, particularly where the focal issue is multinational in its reach. Hence:

Premise 6: Stakeholder engagement should be direct and involving wherever possible. Alternatively, stakeholder reactions to unfolding events around the focal scenario issue should be understood by roleplaying simulation if their direct involvement cannot be achieved. 
Those stakeholders who 'own' the focal issue and will be directly impacted by its outcomes must be engaged as active participants in the scenario process. All other stakeholders who can impact the issue, particularly where currently lacking interest, should be engaged if possible, but must be actively roleplayed if not.

Having set out six conceptual premises on how a PRSA approach to scenario development and use should be framed in order to maximise the potential for meaningful and successful participative engagement by all stakeholders, we now consider the methodological implications for the scenario process.

\section{Building a conceptual model for PRSA implementation}

Volkery and Ribeiro (2009) consider the use made of scenario insights to be problematic within multi-organizational contexts. They note that, "(e)ven well- constructed, thoroughly analyzed scenarios can be of little use and relevance, if the organizational capacity to absorb them is poor, if there is no political backing or if relevant specifics of the policy-making process have not been taken into account" (p. 1199). These authors argue that participants need to 'trust' the constructed scenarios - here trust is defined as: trust in those who develop the scenarios; reliability of information within the scenarios, and; methodological credibility. Also, they note that scenario interventions can clash with the established routines of political decision making and may 'touch upon' vested interests about policy priorities. Apart from these political factors, they go on to note problematic issues to do with the skills of the facilitators, and the level of involvement of participants with the scenario process.

\subsection{Trust in participation and reliability of information}

Kahane $(2012,2017)$ stresses the fundamental importance of strong facilitation and putting aside differences to focus on areas for potential shared benefit, in line with Flyvbjerg (1998) and Vangen and Huxham $(2003,2012)$. In the context of the South Africa project, the success of such an approach led to all key decision-making stakeholders being involved and embedded in the process and committed to collaborative working to build the 'greater wisdom' to which Kahane $(1998,2012)$ refers, with subsequent deep impacts on the country both internally and internationally. However, if there had been no such commitment established at the outset, we must then contemplate what might have happened in South Africa had a range of divergent and conflicting values led to presentation of alternative 'rationalities' - these defined by different power relations and forming the foundation of alternative 'realities' that were incommensurable, each underpinned by a different rationalization presented as rationality. In such contexts, it would be difficult to get the powerful to take part in a common scenario development process to aid their understanding and appreciation of differing perspectives on an unfolding future.

As we have posited in our six premises, the likelihood of success in moving from mutually-agreed scenarios and related actions to long-term benefit for the immediately involved community, that is not negated by powerful external actors, must be grounded in stable power relations and trust between parties, but with acceptance that there will be differences of values, beliefs and resultant presentations of what counts as rationality and 
reality for different groups. As such, trust between parties must include acceptance of these different word-views, while belief in the reliability of information must be built upon open critical discourse about the bases and merits of competing rationalities. Herein lies the most challenging aspect of building the foundations for a successful scenario program.

Kahane's $(1998,2012)$ South Africa project offers a vision of what a successful participatory engagement scenario project might look like. However, it does not in itself offer a generalizable 'formula' for such an approach, only an illustrative example that is entirely context- and actor-dependent for its particular outcomes. His later work (Kahane, 2017) offers some broad guidelines for addressing facilitation in the face of strongly conflicting and entrenched values. For us, however, the question remains, what kind of general guidelines might be offered for a PRSA approach that is more likely - than any current model of scenario development, but not guaranteed - to lead to an Aristotelian phronetic outcome for the 'good of man' (sic)?

\section{Augmenting scenario method through a Power-Rationality Scenario Analysis (PRSA) model}

As might be gathered from the title of this section, what we now outline is not a new approach to scenario development. Rather, it is a novel and innovative integration of several extant modes of inquiry and analysis, with key foci on the nature of power and power relations between stakeholders, and on the essential consideration of time - specifically change over time - as a key influencer of these relations. The model that we offer is general in its broad nature but is entirely context-dependent in terms of its implementation and, thereby, its likelihood of bringing about meaningful and long-term change for human betterment.

The premises we have set out above offer no detailed 'menu' or 'roadmap' on how to build a practical model of what we term Power-Rationality Scenario Analysis (PRSA). The six key premises outline the fundamental essence of such a model, but we accept that a practical framework that is to be successful needs to be constructed both from the top downin terms of fundamental principles and aims - and from the bottom up, in relation to being contextually grounded, engaging with and for all stakeholders, and addressing individual and group objectives, values and beliefs. Below, we proffer some practical suggestions on steps to be taken to enact PRSA by a grouping of less-than-powerful stakeholders.

We set out the model in terms of a set of stages of analysis, synthesis, implementation and reflection, where these are iterative rather than strictly linear.

\section{Stage 1: Focal Issue Determination:}

Define the 'focal issue' in as few words as possible, but with clarity of shared meaning for all participants; e.g. 'Provision of sustainable public transport for all citizens, with zero emissions by 2030'.

The first stage in building a scenario program is crucial, in terms of setting out the key focus of the investigation. Literature on inter-organizational collaboration (Vangen \& Huxham, 2003, 2012) argues the need for a very clear and specific shared focus, to which all participants are committed. The example provided here defines what is a complex, 
multidisciplinary problem that will be impacted by the full range of PESTEL factors. It may be contested in terms of political and economic priorities, technological realisation, etc. Yet, it is stated in few words, summarising four key performance requirements (which we assume have been established and committed to by the affected stakeholders), namely: public (not private) transport; for all community members (not a limited set); zero omissions by a set date and; first and foremost, sustainable (not time-limited).

\section{Stage 2: Scenario Method Selection:}

Select the most appropriate method to meet timescale of participants and purpose of exercise; exploratory, investigative, analytic, testing, etc.

The selection of the most appropriate scenario method is dependent on resource availability, including time from key participants, the nature of understanding of the current status of the problem and the purpose of the exercise. In the above example, there may be a call for exploration of alternative transport forms - trains, trams, buses, bikes - or of the means of implementing just one, such as an agreed tram network. The context of current political and economic commitments may be settled and supportive or may be uncertain and contested. Selection of method must be based on contextual need, not imported expertise. If the focal issue has not yet been defined in concise and agreed terms, there may be a need for a short, investigative scenario exercise (cf. Cairns \& Wright, 2018). Exploration of a welldefined issue may be undertaken using a range of methods, as appropriate: La Prospective (cf. Godet, 1982, 1986) to elicit and examine a desired positive future; BLM (cf. Wright \& Goodwin, 2009) to formulate and interrogate extreme futures, both positive and negative; or one of the 'augmented' IL methods (cf. Cairns \& Wright, 2018) to build a range of scenarios from the present into the future.

\section{Stage 3: Stakeholder Identification:}

Determine the full range of stakeholders who will impact and/or be impacted by the focal issue over the scenario timeframe. Plot current status of stakeholders as in Figure 1. Consider relationships with focal issue.

Starting with an overview of the present situation, elicit ideas from all participants on the 'broad' stakeholder constituency - all who can affect or be affected by the focal issue, both now and into the future (cf. Freeman \& Reed, 1983). Ensure that all relevant sub-sets of generic forms (e.g. politicians, media, businesses) are identified, particularly where differences of values, priorities and power relations might prove crucial to how one future or another might unfold or be inhibited.

\section{Stage 4: Scenario Development:}

Develop the relevant number of scenario storylines in accordance with the selected method, ensuring testing for plausibility and possibility through critical discussion; including roleplay, Devil's advocacy challenge, etc.

Here, participants should follow the selected scenario method. While external expertise in scenario facilitation may be sought and be useful, it is essential that the involved and affected stakeholder owners of the focal issue be engaged and embedded in the program of scenario building. However, it must also be noted that their views on any topic may be 
bounded by a particular rationality and that this rationality may not be shared by others, particularly external and powerful parties. It is crucial that the logic and plausibility of scenarios be rigorously tested through critical analysis using methods such as role-play and Devil's advocacy challenge (cf. Cairns \& Wright, 2018).

\section{Stage 5: Strategy Development and Testing:}

Develop a set of strategies for response to the full set of scenarios, to meet the defined needs of the community of stakeholders that 'own' the focal issue of concern.

As we have argued elsewhere (Wright, Bradfield \& Cairns, 2013), scenarios are not in themselves plans for action. They are ways of understanding how the future might unfold that can inform the development of appropriate strategic planning approaches to be prepared, proactive and resilient in the face of whatever might reasonably happen. This article is not concerned with the strategic planning process per se, but we argue that scenarios and strategies have a symbiotic relationship, where each informs and is informed by the other, and both must be considered in an iterative process of development, testing, refinement and ongoing review.

\section{Stage 6: Stakeholder Impact/response Assessment:}

For each of the developed strategies, consider the involvement and impact for each stakeholder group, with reference to Figure 2. Produce a stakeholder mapping (Table 1) for each strategy/scenario combination. Note that stakeholder positions will vary across scenarios, are not necessarily static over time, and are linked by relations of power and interest.

Stage 6 should not be considered purely sequential, to follow Stage 5. Having constructed an initial stakeholder matrix at Stage 3, that model should become a dynamic tool for application along with Stage 5. As different futures are considered and strategies development, the role of powerful stakeholders becomes central to testing the logic of the narratives and likely success, or otherwise, of strategic choices, where success in considered in terms of these stakeholders. However, when it comes to consideration of phronetic 'good' for all stakeholders, thinking must be expanded beyond what the powerful may or may not do, to consider what the likely impacts of any strategic choice will be for the powerless, the excluded, and future generations.

\section{Stage 7: Develop Policies and Plans to Meet Strategic Response to Focal Issue:}

Develop clear, unambiguous policies and plans that respond to the range of scenarios, that meet the strategic needs of the key stakeholders who own the focal issue, and that define what actions are to be taken by whom and with what resources. Importantly, consider and define actions that are necessary to engage powerful stakeholders whose interests do not align with the focal issue owning community.

In the same way that scenarios are not plans, strategies are not necessarily set out in terms that lead to easy translation to action. While they establish the broad aims and objectives of the organization or community, there are likely key unanswered questions relating to: what needs to be done; when it must be done, and; who is responsible for making sure that it happens. This is the domain of policy and planning. When dealing with complex 
and ambiguous issues with broad social, economic or ecological impacts - for the immediately affected stakeholder community and beyond - there are likely policy implications that must be pursued at the appropriate legislative level. If key policies are not put in place, other competing priorities may well take precedence. For those responsible for operationalising strategic objectives, there is a need for planning, with clearly defined actions to be undertaken and lines of responsibility and reporting for ensuring this happens.

\section{Stage 8: Ongoing Critical Assessment of Progress and Refinement of Process:}

Have a clear program of continual assessment of progress in implementation of policies and plans, and identification of deviations from and blockages to progress. Be prepared to undertake minor refinement as work progresses, or to return to any of the above stages if deviation/blockage occurs.

Whatever scenarios are developed, and whatever strategies, policies and plans are put in place to respond to them and to the focal issue, the future remains uncertain and unpredictable. No matter how broad and inclusive our thinking, there will always be the chance of some 'black swan' (Taleb, 2007), high impact and unpredictable event. All the stages outlined here must be considered dynamic and iterative, not fixed and linear. As we proceed to implement plans to respond to the initial focal issue, we must consider the possibility that even the issue itself has waned in importance. For example, what is the significance now of a drop-off in tourist numbers post-911 to an island nation faced with rising sea levels and storm surges as a result of climate change (particularly when the issue of climate change itself is contested by the most powerful decision makers on the planet)? The future, whatever it may be, must be a context for ongoing vigilance, reappraisal of the recent past and willingness to redesign responses to the future that is unfolding.

\section{Summary, conclusions and limitations}

Our key aim in developing this paper and the PRSA model outlined is to respond to what we see as a lack of critical evaluation - both formal and long-term - of scenario implementation projects, particularly with regard to their relationship with those stakeholders who are not directly involved in the process. As we have discussed, non-involved stakeholders may be of a variety of forms.

First, they may be those that are remote and excluded from consideration, but who may well be impacted by any emergent decisions and actions over time. With these groups and individuals, our concern is for the possibility that they may be negatively impacted by such actions, whether deprived of resources, income or opportunity. In our model, we seek to ensure that the values and interests of such stakeholders are considered from the outset.

Second, those stakeholders that are not directly involved may constitute a latent power/rationality threat to the well-intentioned decisions and actions that emerge from the involved actors' scenario work. Where a local/regional project is undertaken to identify a 'best case' alternative future to that indicated by a trajectory from recent past through present to unfolding future, this future may well be counter to the interests of external stakeholders, but with strong interests in the future in the context of analysis. If these parties' interests - 
whether financial, political, or some other form - are threatened, they are likely to mobilise their own power relations in order to disrupt or derail the program.

As we have highlighted with reference to the almost two-decade study by Flyvbjerg (1998), such powerful actors may readily construct alternative narratives to those of the local best-case scenario. Their own 'best case' may well be underpinned by an alternative rationality - a rationalization of appropriate facts, ideas, opinions, 'alternative facts' and 'false truths' presented as 'reality' to underpin and drive their own case. While we have argued that likely success in building long-term positive outcomes from a scenario program requires, first, the establishment of stable power relations, we recognise that this may be a very difficult, if not nigh impossible aspiration. However, we consider that entry into any program where there are unresolved conflictual power relations, and divergent rationalities that remain covert and unaddressed is most likely doomed to failure from the outset.

While we can offer no panacea for addressing self-interested parties, we hope that the practical step-by-step realisation of our conceptualisation that we present, and the six premises that underpin it will provide a framework for more transparent and inclusive scenario analysis. We hope that it will encourage opening up of critical debate on the multiple 'realities' that exist across diverse stakeholder groups, and on the potentially competing rationalities that underpin them. Specifically, we hope that it will prompt thinking on Aristotle's intellectual virtue of phronēsis, thinking to inform action for the good of humanity at large. Finally, we hope that it will encourage ongoing engagement and collaboration with all stakeholders over an extended time period, to provide the greatest chances of long-term success in achieving phronetic outcomes.

\section{References}

Allcott, H. and Gentzkow, M., 2017. Social media and fake news in the 2016 election. Journal of Economic Perspectives, 31(2), pp.211-36.

Arendt, H. (1970). On Violence. Houghton Mifflin Harcourt.

Aristotle. (1976/2004). The Nicomachean Ethics (J.A.K. Thomson, Trans., 1953; H. Tredennick, Rev., 1976), London: Penguin Books.

BBC News, 2018. Trump lawyer Rudy Giuliani defends 'truth isn't truth' remark. $B B C$ News, 20 August. Sourced, August 22, 2018, from https://www.bbc.com/news/world-uscanada-45252493

Beech, N. and Cairns, G., 2001. Coping with change: The contribution of postdichotomous ontologies. Human Relations, 54(10), pp.1303-1324.

Bellamy, A.J., 2011. Libya and the responsibility to protect: The exception and the norm. Ethics \& International Affairs, 25(3), pp.263-269.

Bourgeois, R., Penunia, E., Bisht, S. and Boruk, D., 2017. Foresight for all: Co-elaborative scenario building and empowerment. Technological Forecasting and Social Change, 124, pp.178-188.

Bryant, B.P., Lempert, R.J., 2010. Thinking inside the box: a participatory, computer assisted approach to scenario discovery. Technol. Forecast. Soc. Chang. 77, 34-49. 
Cairns, G., Goodwin, P., \& Wright, G. 2016. A decision-analysis-based framework for analysing stakeholder behaviour in scenario planning. European Journal of Operational Research, 249(3), 1050-1062.

Cairns, G., Śliwa, M. and Wright, G., 2010. Problematizing international business futures through a 'critical scenario method'. Futures, 42(9), pp.971-979.

Cairns, G. and Wright, G., (2018). Scenario Thinking (2 ${ }^{\text {nd }}$ ed.): Preparing your organization for the future in an unpredictable world. London: Palgrave Macmillan.

Cairns, G., Wright, G., Fairbrother, P. and Phillips, R., 2017. Branching Scenarios. Seeking Articulated Action for Regional Regeneration-A Case Study of Limited Success. Technological Forecasting and Social Change. https://doi. org/10.1016/j. techfore, 14.

Conway-Smith, E. 2014. 20 years since apartheid: What' changed in South Africa, and what hasn't. GlobalPost, 27 April. Sourced, August 17, 2018, from

https://www.pri.org/stories/2014-04-27/20-years-apartheid-whats-changed-south-africaand-what-hasnt

Cornelius, P., Van de Putte, A. and Romani, M., 2005. Three decades of scenario planning in Shell. California management review, 48(1), pp.92-109.

Dahl, R. A. (1967). Pluralist Democracy in the United States: conflict and consent. Rand McNally.

de Villers, J. 2018. South Africa dropped to the $105^{\text {th }}$ happiest country in the world - even dictatorships and occupied territories are happier. Business Insider SA, 14 March.

Sourced, August 18, 2018, from https://www.businessinsider.co.za/south-africa-drops-to105th-on-worldwide-happiness-report-continuing-downward-trend-2018-3

Dowie, A. 2000. Phronesis or 'practical wisdom' in medical education. Medical Teacher, 22(3), pp. 240-241.

Flyvbjerg, B. (1998). Rationality and power: Democracy in practice. Chicago, IL: University of Chicago Press.

Flyvbjerg, B. (2001). Making social science matter: Why social inquiry fails and how it can succeed again. Cambridge: Cambridge University Press.

Flyvbjerg, B. 2003. Making organization research matter: power values and phronesis, in: B. Czarniawska, G. Sevo'n (Eds.), The Northern Lights: Organization theory in Scandinavia. Copenhagen: Liber Abstrakt-Copenhagen Business School Press, Copenhagen, pp. 357-382.

Foucault, M., Morris, M. and Patton, P. (1979). Michel Foucault: Power, Truth, Strategy. Sydney: Feral Publications.

Freeman, R.E. and Reed, D.L., 1983. Stockholders and stakeholders: A new perspective on corporate governance. California Management Review, 25(3), pp.88-106.

Gershman, M., Bredikhin, S. and Vishnevskiy, K., 2016. The role of corporate foresight and technology roadmapping in companies' innovation development: The case of Russian state-owned enterprises. Technological Forecasting and Social Change, 110, pp.187195.

Godet, M., 1982. From forecasting to 'la prospective': a new way of looking at futures. Journal of Forecasting, 1(3), pp. 293-301.

Godet, M., 1986. Introduction to la prospective: seven key ideas and one scenario method. Futures, 18(2), pp.134-157. 
Godet, M., 2010. Future memories. Technological Forecasting and Social Change, 77(9), pp.1457-1463.

Green, K.C. and Armstrong, J.S., 2011. Role thinking: Standing in other people's shoes to forecast decisions in conflicts. International Journal of Forecasting, 27(1), pp.69-80.

Jefferson, M., 2012. Shell scenarios: What really happened in the 1970s and what may be learned for current world prospects. Technological Forecasting and Social Change, 79(1), pp.186-197.

Kahane, A., 1998a. Changing the winds. Whole Earth, 96, pp.77-81.

Kahane, A., 1998b. Learning from Mont Fleur: scenarios as a tool for discovering common ground. Deeper News, 7(1), pp.1-4.

Kahane, A. (2012). Transformative scenario planning: Working together to change the future. Berrett-Koehler Publishers.

Kahane, A. (2017). Collaborating with the Enemy: How to work with people you don't agree with or like or trust. Berrett-Koehler Publishers.

Marx, K. and Engels, F. (1888/1967). The Communist Manifesto. Penguin Books.

Montgomery, M., 2017. Post-truth politics?. Journal of Language and Politics, 16(4), pp.619-639.

Nietzsche, F. (1968). The Will to Power. Trans. W. Kaufmann (Ed.) \& R.J. Hollingdale. New York: Vintage Books.

Oteros-Rozas, E., Martín-López, B., Daw, T.M., Bohensky, E.L., Butler, J.R., Hill, R., Martin-Ortega, J., Quinlan, A., Ravera, F., Ruiz-Mallén, I. and Thyresson, M., 2015. Participatory scenario planning in place-based social-ecological research: insights and experiences from 23 case studies. Ecology and Society, 20(4).

Poole, C., 2018. The World's Largest Oil \& Gas Companies 2018: Royal Dutch Shell Surpasses Exxon as top dog. Forbes. Sourced, August 16, 2018 from https://www.forbes.com/sites/clairepoole/2018/06/06/global-2000-oilgas/\#79e4f1cc1d1b

Ramos, J.M., 2006. Dimensions in the confluence of futures studies and action research. Futures, 38(6), pp.642-655.

Rickards, L., Wiseman, J., Edwards, T. and Biggs, C., 2014. The problem of fit: scenario planning and climate change adaptation in the public sector. Environment and Planning C: Government and Policy, 32(4), pp.641-662.

Roth, K., 2004. War in Iraq: not a humanitarian intervention. Human rights in the 'War on Terror, pp.143-57.

Schoemaker, P.J. and van der Heijden, C.A., 1992. Integrating scenarios into strategic planning at Royal Dutch/Shell. Planning Review, 20(3), pp.41-46.

Shell Global. Undated. Shell Scenarios. Sourced, August 18, 2018, from https://www.shell.com/energy-and-innovation/the-energy-future/scenarios.html

Smith, R., 1999. Paths of judgement: The revival of practical wisdom. Educational Philosophy and Theory, 31(3), pp. 327-340.

Stevenson, T., 2006. From vision into action. Futures, 38(6), pp.667-672.

Suiter, J., 2016. Post-truth politics. Political Insight, 7(3), pp.25-27.

Swaine, J. 2017. Donald Trump's team defends 'alternative facts' after widespread protests. The Guardian, 23 January. Sourced, May 24, 2018, from 
https://www.theguardian.com/us-news/2017/jan/22/donald-trump-kellyanne-conwayinauguration-alternative-facts

Taleb, N. N. (2007). The black swan: The impact of the highly improbable (Vol. 2). Random House.

Van Der Heijden, K., 2000. Scenarios and forecasting: two perspectives. Technological forecasting and social change, 65(1), pp.31-36.

Vangen, S., Huxham, C., 2003. Nurturing collaborative relations: building trust in interorganizational collaboration. J. Appl. Behav. Sci. 39, 5-31.

Vangen, S., Huxham, C., 2012. The tangled web: unravelling the principle of common goals in collaborations. J. Public Adm. Res. 22, 731-760.

Vangen, S., Hayes, J.P., Cornforth, C., 2015. Governing cross-sector, inter-organizational collaborations. Public Manag. Rev. 17, 1237-1260.

Venable, J.M., Ma, Q.L., Ginter, P.M. and Duncan, W.J., 1993. The use of scenario analysis in local public health departments: alternative futures for strategic planning. Public Health Reports, 108(6), p.701.

Volkery, A. and Ribeiro, T., 2009. Scenario planning in public policy: understanding use, impacts and the role of institutional context factors. Technological forecasting and social change, 76(9), pp.1198-1207.

Weber, M. (2009). The Theory of Social and Economic Organization. Simon and Schuster.

Wright, G., Bradfield, R., \& Cairns, G. (2013). Does the intuitive logics method-and its recent enhancements-produce "effective" scenarios?. Technological Forecasting and Social Change, 80(4), 631-642.

Wright, G. and Cairns, G. (2011). Scenario thinking: Practical approaches to the future. London: Palgrave Macmillan.

Wright, G. and Goodwin, P., 2009. Decision making and planning under low levels of predictability: Enhancing the scenario method. International Journal of Forecasting, 25(4), pp.813-825. 


\section{Making scenario interventions matter: exploring issues of power and rationality}

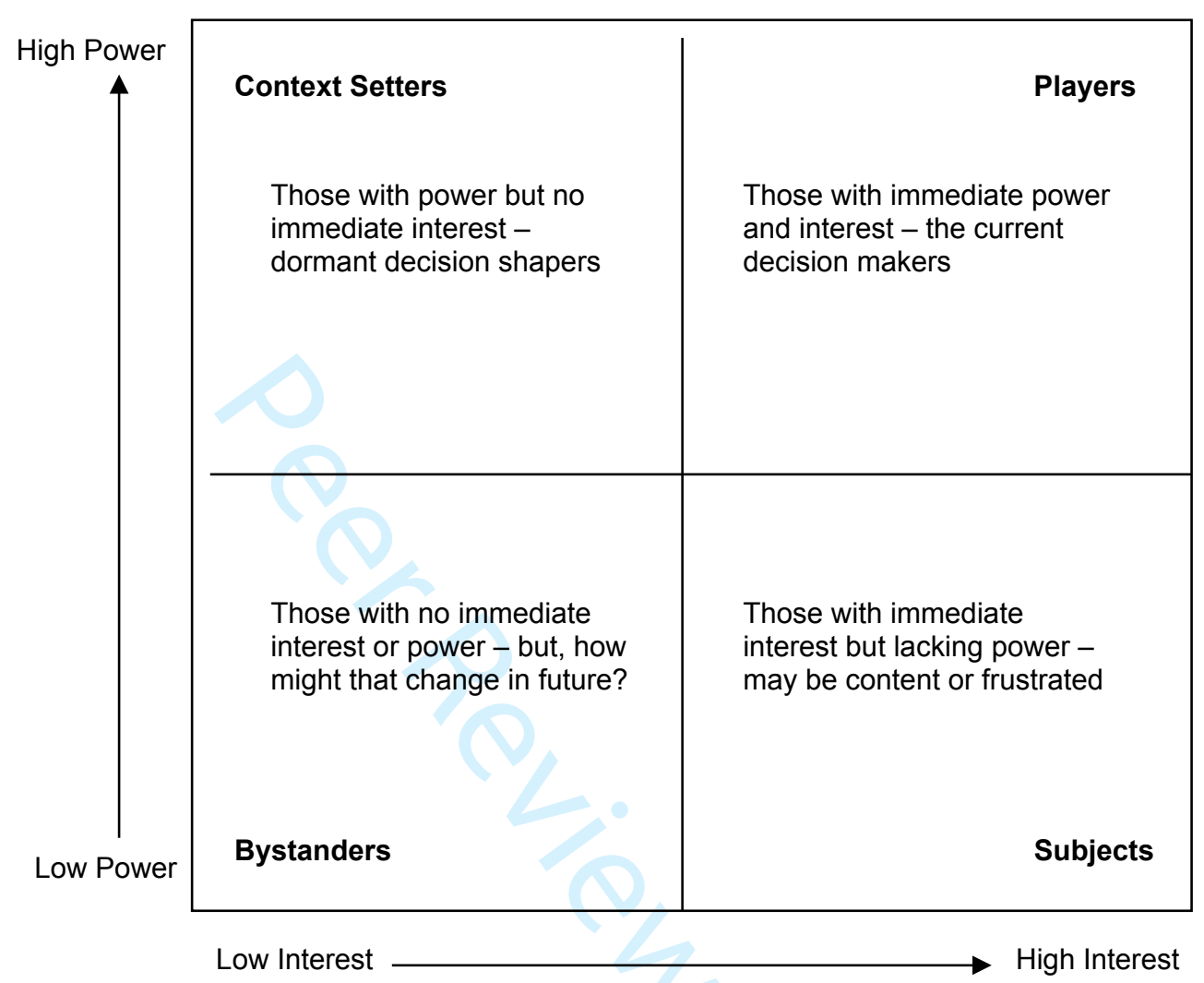

Figure 1 - Stakeholder analysis matrix (adapted from Cairns and Wright, 2018) 


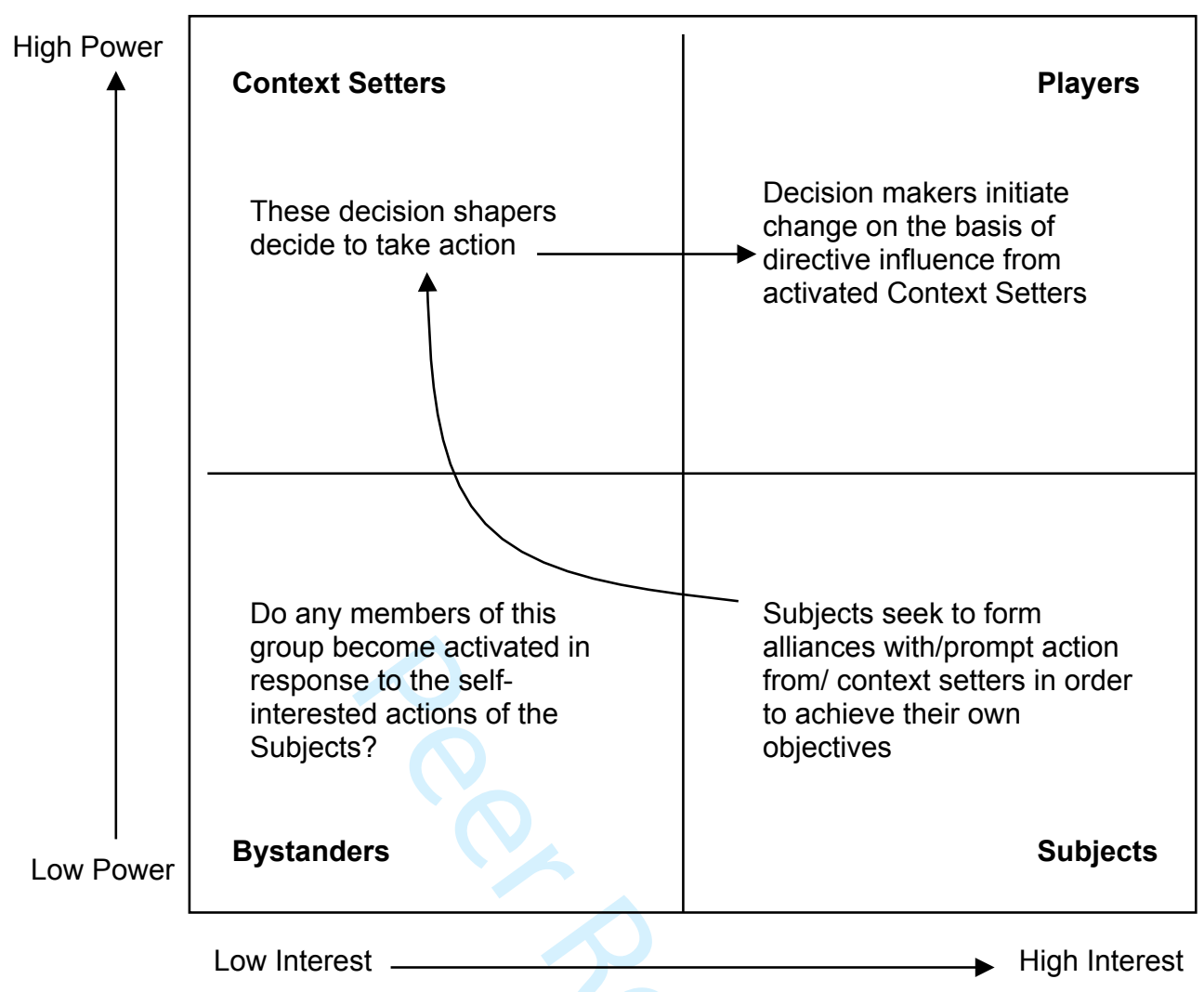

Figure 2 - Stakeholder activation at work (based, in part, on Cairns and Wright, 2018) 
Table 1. Evaluation of the alignment of current stakeholder interests with those of the scenario developers

\begin{tabular}{|l|l|l|l|}
\hline & Positive alignment & Negative alignment & Neutral alignment \\
\hline $\begin{array}{l}\text { Context } \\
\text { Setters }\end{array}$ & $\begin{array}{l}\text { Attempt to activate these } \\
\text { stakeholders to help } \\
\text { achieve your own interests }\end{array}$ & $\begin{array}{l}\text { Monitor these stakeholders } \\
\text { and be prepared to defend } \\
\text { your own position against } \\
\text { these stakeholders }\end{array}$ & $\begin{array}{l}\text { Monitor these stakeholders } \\
\text { and attempt to achieve their } \\
\text { positive alignment with } \\
\text { your own interests }\end{array}$ \\
\hline Players & $\begin{array}{l}\text { Collaborate with these } \\
\text { stakeholders. }\end{array}$ & $\begin{array}{l}\text { Be prepared to defend your } \\
\text { own position against these } \\
\text { stakeholders }\end{array}$ & $\begin{array}{l}\text { Monitor these stakeholders } \\
\text { and attempt to achieve their } \\
\text { positive alignment with } \\
\text { your own interests }\end{array}$ \\
\hline Bystanders & Monitor these stakeholders & Monitor these stakeholders & Monitor these stakeholders \\
\hline Subjects & $\begin{array}{l}\text { Consider collaboration } \\
\text { with these stakeholders. }\end{array}$ & Monitor these stakeholders & Monitor these stakeholders \\
\hline
\end{tabular}

